\title{
Research on the Reform and Development of Journalism Education in Private Colleges and Universities in the Era of Media Convergence
}

\author{
$\mathrm{Si} \mathrm{Xu}{ }^{1, *}$ \\ ${ }^{l}$ School of culture and media, Xi'an Eurasia University, Xi'an, Shaanxi, China \\ *Corresponding author. Email: xusi@eurasia.edu
}

\begin{abstract}
The arrival of the digital economy era further promotes the development of media convergence. Traditional media and new media present cooperation modes different with that in the past. With the development pattern of global integration, the change of media ecology is more intense. The corresponding change is the training mode of media talents. Journalism specialty in private colleges and universities has been committed to the cultivation of high-quality application-oriented talents. In the era of Internet of everything, it is necessary to seize the opportunity of industrial change, give full play to the advantages of education and teaching of subject platform, and integrate the media development concept of media convergence with the application-oriented cultivation of discipline construction, so as to make the undergraduate journalism education in private colleges and universities more advantageous and energetic.
\end{abstract}

Keywords: Media Convergence, Internet of everything, Talent training, Teaching reform.

\section{INTRODUCTION}

In the era of Internet of everything and the rapid development of global convergence communication, the dramatic change of media ecology forces traditional media and practitioners to face the challenge and transformation. The innovation of communication format brings the innovation of communication concept and practical ability, and then affects the innovation of journalism education. In the era of omni-media, in order to match the policy guarantee and external environment suitable for the times and the talent cultivation of convergence media, and to push back the change of talent cultivation mode with the change of external media, its fundamental purpose is to fully motivate human driving force, human creativity and human sustainable development, and fully liberate the vitality of talents.

\section{DEVELOPMENT STATUS OF SHAANXI CONVERGENCE MEDIA}

\subsection{Interpretation of Development Policy of National Convergence Media}

Today, the dissemination of public opinion is undergoing profound changes from its mode, channel and speed to its speed. Against the background of international economic integration, digital economy has become the strategic focus of various countries to promote its development. With the development of globalization, digital economy has become the strategic focus of national development. General Secretary Xi Jinping stressed that promoting the integrated development of media and building an omni-media has become an urgent task for us, while he also provided strong spiritual strength and public opinion support for achieving the "two centenary goals" and the great rejuvenation of the Chinese nation. It is required to deepen understanding of the development of media convergence from the strategic height of the overall cause of the party and the people, grasp the 
significance of the development of media convergence, and better promote the in-depth development of media convergence.

It is suggested to promote the modernization of national governance structure and governance capacity by improving the development of media convergence. In this era of media convergence, the media is not only considered as the main provider and transmitter of its information, but also plays an important role in the process of governance of socialist countries. It achieves the maximization and structural optimization of governance efficiency by communicating social conditions and public opinions, transmitting mainstream voice, and sharing the voice of the party and the people. Therefore, the integration of media is not only seen as a proposition of communication, but also as a proposition of governance. In the face of profound changes in media ecology brought about by new technologies such as mobile Internet and big data, the masses need to constantly deepen their understanding and cognition of the development of media convergence, and promote the deep integration of traditional media and emerging media in their content, channel, platform, operation, management and other aspects in practical work. And then, the modern communication network with the three-dimensional, diversified, integrated development is formed. At the same time, it promotes the relevant policies and systems to be more mature and standardized, transforms the advantages of the communication policy system into the advantages of the communication policy effectiveness, and makes contributions to the modernization of the governance of the party and government.

Promoting the healthy development of international finance and news media can effectively promote and continuously enhance the political, cultural and economic soft power of China. The successful practice of new socialism with Chinese characteristics has enabled China to move to the center of the world, and has expanded the vast space for developed and developing countries to enter the world modernization. More than ever, the world hopes to hear all the voices of China and understand the history of the new era and the whole China of the old era. In order to effectively and continuously enhance the political, cultural and economic soft power of the Chinese nation and developed countries, it is required to tell the historical story of beautiful China, spread the beautiful voice of beautiful China, and present a real, three-dimensional and comprehensive beautiful China to the public all over the world. Therefore, efforts must be made to speed up the establishment of a number of international and firstclass new mainstream news media with strong news communication driving force, guiding driving force and influence. Through the integration and optimization of the cultural business process and the integration and reconstruction of the platforms, it can realize the effective utilization and integration of all kinds of cultural media information resources and production factors, realize the organic integration and mutual connection of media information content, technical means, management system and other means, catalyze the qualitative change of information integration, and enlarge the integration and efficiency of the development of traditional excellent culture, strengthen the integration ability of international cultural communication and the connotation construction of the value system, so as to continuously expand and enhance the comprehensive soft power of the excellent traditional culture of the Chinese nation.

\subsection{Analysis on the Development Status of Shaanxi Convergence Media}

On August 18, 2014, the fourth meeting of the central leading group for comprehensively deepening reform deliberated and approved the "guiding opinions on promoting the integration and development of traditional media and emerging media". Media convergence has become a national strategy, and the implementation path of media convergence has also become the key to the top-level design.

From 2015 to 2020, dramatic changes have taken place in the media ecology. Before 2015, obvious ecological changes have taken place in the media industry every one or two years. In recent years, the frequency of changes in the media industry has increased, and new communication phenomena have occurred almost every half a year, constantly impacting and guiding the audience's cognition. In 2020, intelligent media of everything will become a hot media word. In the post-epidemic period, traditional media and new media play more 
and more diversified roles in the survival chain of the Internet.

Based on the rapid changes of mobile Internet and the arrival of digital economy era, Shaanxi Province, located in the remote western region, actively implements the Party Central Committee's policy on media convergence and the spirit of relevant instructions, and makes greater efforts to promote the extensive and deep integration of traditional media, news media and Internet in the true sense.

\section{ANALYSIS ON THE CURRENT SITUATION OF THE REFORM OF UNDERGRADUATE EDUCATION OF JOURNALISM SPECIALTY IN PRIVATE COLLEGES AND UNIVERSITIES}

Taking Xi'an Eurasia University as a sample, this paper analyzes the education and teaching reform of journalism specialty in private colleges and universities in the era of media convergence. In the era of media convergence, due to the Internet of everything, the progress of artificial intelligent technology and other factors, journalism specialty should keep pace with the times, pay close attention to the changes of media ecology, have insight into the changes of traditional media employment demand, and understand the demand model of Internet and new media for human resources of journalism graduates on the basis of technological blessing. From the industrial demand to the talent training mode, a series of education and teaching reform measures are carried out to achieve seamless docking with the industrial talent demand.

\subsection{Cooperation with Chinese and Foreign Universities to Broaden Students' International Vision}

In cooperation with the school of journalism of the University of Missouri, journalism specialty regularly hold Missouri teaching week every year. Professors from the University of Missouri are invited to teach in the teaching week to broaden students' international vision, and help students gain insight into global changes in journalism. During the teaching week, teachers focus on the frontier of media ecological change. "Mobile news technology and art" in 2016, "UAV application and communication" in 2017, "artificial intelligence and intelligent communication" in 2018, and "media convergence news report" in 2019 have realized the integration and development of "Missouri mode" in journalism specialty, promoted the application and training of practical teaching, focused on the cutting-edge content, and driven the professional transformation.

Focusing on the development and changes of the media industry on both sides of the Taiwan Strait, from 2015 to 2020, professors invited from Shih Hsin University introduced changes in journalism and communication in Taiwan to journalism students, broadening the students' horizons, and promoting the communication of media culture on both sides of the Taiwan Strait.

The creative research camp practiced the practical teaching of application and communication, launched three phases of research and study of Suzhou creative industry, European culture tour and Taiwan urban culture experience, and more than 60 students participated in this activity. In the fields of digital creativity, cultural creativity and new media product design, students' learning boundaries are constantly expanded.

\subsection{Establishing Diversified Application- oriented Teaching Practice Platform and Cultivating Convergence Media Talents}

Journalism specialty has been closely integrated with many local authoritative media and institutions in China and foreign countries, such as Xi'an newspaper media group, Huashang media group, Shaanxi radio and television group, Creative Power, etc. Through the entrance education, cognitive practice, practice in primary and secondary school and professional practice, the whole process of news production will be developed. With the practice of processing workshop and the guidance of industrial tutor, students' homework can be directly transformed into authoritative news works released by the media. And students' practice platform will be expanded. Students are organized to participate in the public welfare campus activities of Shaanxi radio and television grand theater, so as to improve the artistic quality, break the discipline boundaries, and enhance students' practical ability of convergence media communication. Creative Power and other local authoritative media and institutions are closely integrated. 
On the goal of convergence media talent training, an omni-media practice platform is built. Through high-intensity project training of Toutiao training camp, students' new media operation ability is improved. The World Wide Web (Xi'an) provides students with real projects to strengthen their ability of network editing and public opinion observation. In recent years, journalism specialty has continuously delivered interns to the new media center of Xi'an newspaper group, and excellent graduates have been highly recognized by enterprises.

\subsection{Improving Students' Learning Experience Through Curriculum Reform}

Students majoring in journalism specialty have insight into the changes in the global journalism, understand the industrial changes, and know the reform and innovation of talent training mode. Curriculum reform should be carried out to meet the needs of talents in the changing media ecological environment. "Creative Writing", a key course at the university level, improves students' ability of creative writing by classifying course modules, and provides creative content with multiple scenes and users' demands. "Introduction to Journalism", the core professional course, is taught in cooperation with professors from Shih Hsin University, professors from School of Journalism, University of Missouri, and senior media experts against the background of the global change of journalism, so as to broaden students' perspective of globalization and grasp the law of the development of journalism. According to "News Gathering and Writing", the media channels will be set up, students' practice will be promoted by real proposition, and the output platform of students' works will be established. "News Editor" applied for the key course at the university level, expanded the direction of multimedia editing, and realized the cultivation of students' compound ability by updating the course teaching module. "Virtual simulation teaching project in whole process of producing convergence news products" is set up in "Convergence News", effectively integrating theory teaching and virtual simulation experiment deeply, expanding the breadth and depth of undergraduate practice teaching, and ensuring the quality of practice teaching.

With the introduction of field investigation, more than 20 students majoring in journalism participated in CEEE project research, and went deep into rural areas to conduct social investigation on preschool education. With the extension of media investigation and statistics course, participation in real projects is helpful to improve students' investigation abilities.

Industrial teachers cooperate in teaching. Senior industrial experts are invited to cooperate with module teaching, special lectures, practical project guidance and graduation design of the course to continuously expand students' professional vision. And students' learning engagement will be enhanced according to diversified teaching modes. The well-known documentary directors are invited to share the patriotism of the era recorded by camera. In April every year, creative masters of world-famous advertising companies teach students creative classics, share creative design ideas, stimulate students' creative thinking and cultivate their innovative abilities.

Students are organized and guided to participate in the professional competition, and students' learning experience of the course will be enhanced. For Journalism specialty, it introduces the national authoritative subject competition into the course teaching. Through national data news competition, the students' ability of data analysis, mining and visualization will be strengthened. Taking part in the college award and the grand competition, students' innovation ability will be stimulated. The industrial competition, public service advertising competition and subject competition are organized with cooperative enterprises, so as to promote zero distance between teaching and industry demand, give full play to the flexibility of practical teaching, and improve students' participation in learning.

\section{THE DEVELOPMENT OF CONVERGENCE MEDIA COMMUNICATION ERA FORCES THE REFORM OF TALENTS TRAINING IN JOURNALISM SPECIALTY}

Media convergence, in the final analysis, refers to "human integration". According to "opinions on accelerating the development of media convergence", the general requirements of "promoting the development of media convergence in depth" are clearly put forward, and the two keys of "deepening the reform of system and mechanism and increasing the training of omni-media talents" are emphasized. These two keys are the key factors 
for the vertical development of media convergence in depth.

Journalism specialty in private colleges and universities cultivates convergence media talents. Focusing on the production and integrated communication of high-quality information content in the field of traditional and new media, journalism specialty aims to cultivate comprehensive applied talents who have the professional ability of reporting, writing, editing and shooting, give consideration to creative expression and social insight, pay attention to the development trend of Chinese and foreign media industry, master the law and art of communication, and can adapt to the rapid changes of media. In fact, there are two definitions of convergence media talents: omnimedia talents and experts. Omni-media talents refer to the talents who can meet the requirements of omni-media business in the era of convergence media. .. Experts refer to the talents who can play a role in the vertical business of omni-media format.

What kind of changes must be made in the journalism specialty of private undergraduate university to keep up with the rapidly changing context of the media industry? The journalism and communication is a highly practical discipline. Working with the industry to establish experiential learning, in which students can experience the latest forms of media coverage in a real and intense working environment, is an effective way of dialogue between the academia and the industry.

\section{EXPLORATION ON THE PATH OF TRAINING APPLIED TALENTS IN JOURNALISM SPECIALTY AGAINST THE BACKGROUND OF CONVERGENCE MEDIA DEVELOPMENT}

Over the years, the professional classroom education of journalism specialty in private colleges and universities has always adhered to the educational concept of "student centered". From the perspective of high quality, this paper puts forward the mutual adaptation in three aspects: the goal of education and the demand for society, the process of education and the characteristics of students, the commitment of quality and the acquisition of resources. Starting from the important aspects of specific high-quality professional classroom, highquality education is provided for students. In addition, it is necessary to protect high-quality education from the important aspects of specific quality education.

Private undergraduate education should regard quality as the lifeline of the healthy development of the school in the future, and always adhere to the "student-centered" concept and scientific development. When the campus environment, curriculum quality, practical teaching, international education and other conditions are improved and optimized, it is necessary to think about the future development of students.

\subsection{Paying Attention to Students' Development}

The classroom education and practice of applied journalism should always pay attention to the teaching of journalism. For "education", it is not to put all things in a basket, but to light a bright light.

Students accept higher education in school, enriching themselves, tapping their potential at the best age, trying to become diversified talents, keeping their enthusiasm for the unknown, and yearning for a better life with high quality after graduation, going to work and even in the future life.

"School + teachers + students" is the closedloop structure of education. When schools and teachers are improving at the same time, it is more important to improve students' overall cognition and professional level. In recent years, taking a panoramic view of the postgraduate entrance examination of journalism specialty, the proportion and success rate of postgraduate entrance examination are constantly improving. Schools can better learn from the successful experience, so that students can not only make a breakthrough and improve in practice, but also return to original nature. Students can learn to think, learn to treat problems dialectically, improve academic and English level, and make a good plan for future career and go further. That is to say, students can understand their original natures.

\subsection{The Development of Omni-media Teachers}

In terms of the values and feelings of higher education, the high-quality education enables both college students and class teachers feel the beauty of this kind of education. A kind of education that can make everyone feel happy and practical, and make everyone have a sense of achievement and 
pride is high-quality education. The most eternal content of education is to let teachers fall in love with education, have the enthusiasm for education, have the motivation and ability of education, and let every student grow up together according to their original state. Students don't need to spend too much time and tuition to receive good environmental education. And enterprises like fresh university graduates.

\subsection{The Course Construction Should Be Carried Out with the Idea of Platform}

Always, the production of high-quality content has always been the core competitiveness of China's network communication industry. For the construction of core courses, it is necessary to seriously consider how to meet the industrial needs and actively participate in all aspects of industrial development and production. ...

Therefore, with the development of convergence media industry, taking creative writing course as an example, creative writing course has been regarded as the upstream field of cultural and creative industry in the discipline field. At the same time, creative writing, as the core field of content production, can be written and produced in many fields, such as WeChat, Weibo, short video, film and television screenwriter, cultural creation, etc. At the same time, the course of creative writing can also be closely combined with the traditional Chinese culture. It can not only be combined with the current upsurge of big Chinese and traditional Chinese cultures, help the national strategy of cultural power, cultivate cultural confidence of students, but also connect with the concept of running high-quality private colleges and universities. Starting from the course, it can help students develop their own specialties by combining students' thinking and expression ability, learning ability and creative expression ability, and lay a good foundation for the stable development of students' future academic career.

\subsection{Paying Attention to the Construction of High-quality Specialty}

In the face of increasingly complex media environment and public demand, if the news media want to further maintain its dominant position, it must conform to the communication mode of the convergence media, and constantly realize the sustainable development of the news media through the innovation of ideas, contents and methods. It is true for journalism. The concept of high-quality education of private universities is not so much a strategic plan for the future, as it is a discipline development path that is suitable for applicationoriented talent training and the current era selected by careful insight into the law of social development. With the dramatic changes of media environment, it is required to provide students with strong professional competitiveness, so that students can have outstanding performance in the future talent competition market. In order to improve the quality of professional education and teaching, it is necessary to carry out more detailed market investigation and make accurate talent development planning. Based on the precipitation and accumulation of the original professional development, it is suggested to systematically sort out and think about the international development direction of the specialty, and form enough influence in bringing in and going out. Through the construction of high-quality courses, it can enhance students' high-quality learning experience, and improve the quality of professional personnel training, so that the graduates of journalism can really have the right to speak in the field of Pan communication, and become high-level talents in the industry within 4-5 years after graduation.

High-quality education is to teach students in accordance with their aptitude, to let students grow according to their original appearance, to uphold a fair heart, to take good care of every student, to help students start from learning, to learn all their lives, to constantly make the improvement, and to strive to pursue and realize their ideal of life. The concept of running high-quality school can be continuously promoted and deepened in practice, making students happy in learning, teachers happy in teaching, and society and industry have higher satisfaction.

\section{CONCLUSION}

Under the thinking of cultivating convergence media talents, the concept of all-round talent cultivation can be seen. Whether it is internationalization, application, curriculum reconstruction, student development or digital transformation, journalism specialty focuses on long-term development and lifelong learning. It also makes educators in private colleges and universities deeply realize that instead of worrying about whether the existing knowledge can make students adapt to the unknown future, they should pay more attention to the cultivation of students' 
unchanging ability. Teachers do not be gardeners or prune the garden, just be solid trees, improve the level of teaching design and interdisciplinary ability, use resources to leverage resources, and use their own words and deeds to influence others.

Real education is to use a tree to shake another tree, use a cloud to push another cloud, and use a soul to wake another soul.

\section{AUTHORS' CONTRIBUTIONS}

This paper is independently completed by $\mathrm{Si} \mathrm{Xu}$. gathering and editing talent training system in the era of integrated media [J]. Media Forum, 2020, 3(11). (in Chinese)

[9] Wang Xia. The change and continuation of news production in a liquid society - Based on a hierarchical interview with news client $\mathrm{M}$ [J]. International Journalism, 2019(05): 60-79. (in Chinese)

[10] Su Jingyi. An analysis of the way to integrate journalism education $[\mathrm{J}]$. News Forum, 2020(04):117-119. (in Chinese)

\section{REFERENCES}

[1] Chandrama Acharya. OutcomeBased Education (OBE): A new Paradigm for Learning [J].CDTLink, 2003, 7 (3): 27-37.

[2] People's Daily. Wu Yan, Chief of Ministry of Higher Education: 2019, Full-scale Undergraduate Education [EB/OL]. (2019-0126) [2019-04-10]. http://edu. people.com.cn/n1/2019/0126/c100630591682.html.

[3] Jiang Wenji. On the Reform of Practice Teaching of Journalism in Colleges and Universities - Taking the Journalism Department of North Minzu University as an example[J]. News Window, 2013(6). (in Chinese)

[4] Outline of the National Medium and Longterm Education Reform and Development Plan (2010-2020) [EB/OL]. Xinhuanet. http://education.news.Cn/201007/29/c_12389320_11.htm, 2010-07-29.

[5] Song Yajuan, Zheng Zilin. How to train journalism and communication students: exploring the quality requirements of journalism talents in the omni-media environment in the era of new media (part 2) [N]. Guangming Daily, 2014-05-03. (in Chinese)

[6] Peng Lan. Four key changes in the direction of media integration [J]. Young Journalist, 2009 (6). (in Chinese)

[7] Jiang Fei. Reflections on the training of future international journalism talents in the new era [J]. News and Writing, 2020(07). (in Chinese)

[8] Yan Tianhong. The construction and realization of the higher vocational news 